\title{
Nonstarter Lactobacillus Strains as Adjunct Cultures for Cheese Making: In Vitro Characterization and Performance in Two Model Cheeses
}

\author{
M. Briggiler-Marcó, M. L. Capra, A. Quiberoni, G. Vinderola, J. A. Reinheimer, and E. Hynes ${ }^{1}$ \\ Instituto de Lactología Industrial Facultad de Ingeniería Química, Universidad Nacional del Litoral-CONICET Santiago del Estero 2829 , \\ S3000AOM Santa Fe, Argentina
}

\begin{abstract}
Nonstarter lactic acid bacteria are the main uncontrolled factor in today's industrial cheese making and may be the cause of quality inconsistencies and defects in cheeses. In this context, adjunct cultures of selected lactobacilli from nonstarter lactic acid bacteria origin appear as the best alternative to indirectly control cheese biota. The objective of the present work was to study the technological properties of Lactobacillus strains isolated from cheese by in vitro and in situ assays. Milk acidification kinetics and proteolytic and acidifying activities were assessed, and peptide mapping of trichloroacetic acid 8\% soluble fraction of milk cultures was performed by liquid chromatography. In addition, the tolerance to salts $(\mathrm{NaCl}$ and $\mathrm{KCl})$ and the phage-resistance were investigated. Four strains were selected for testing as adjunct cultures in cheese making experiments at pilot plant scale. In in vitro assays, most strains acidified milk slowly and showed weak to moderate proteolytic activity. Fast strains decreased milk pH to 4.5 in $8 \mathrm{~h}$, and continued acidification to 3.5 in $12 \mathrm{~h}$ or more. This group consisted mostly of Lactobacillus plantarum and Lactobacillus rhamnosus strains. Approximately one-third of the slow strains, which comprised mainly Lactobacillus casei, Lactobacillus fermentum, and Lactobacillus curvatus, were capable to grow when milk was supplemented with glucose and casein hydrolysate. Peptide maps were similar to those of lactic acid bacteria considered to have a moderate proteolytic activity. Most strains showed salt tolerance and resistance to specific phages. The Lactobacillus strains selected as adjunct cultures for cheese making experiments reached $10^{8}$ cfu/g in soft cheeses at $7 \mathrm{~d}$ of ripening, whereas they reached $10^{9} \mathrm{cfu} / \mathrm{g}$ in semihard cheeses after $15 \mathrm{~d}$ of ripening. In both cheese varieties, the adjunct culture population remained at high counts during all ripen-
\end{abstract}

Received March 8, 2007.

Accepted June 13, 2007.

${ }^{1}$ Corresponding author: ehynes@fiqus.unl.edu.ar ing, in some cases overcoming or equaling primary starter. Overall, proximate composition of cheeses with and without added lactobacilli did not differ; however, some of the tested strains continued acidifying during ripening, which was mainly noticed in soft cheeses and affected overall quality of the products. The lactobacilli strains with low acidifying activity showed appropriate technological characteristics for their use as adjunct cultures in soft and semihard cheeses.

Key words: nonstarter lactobacilli, acidifying activity, proteolytic activity, cheese making

\section{INTRODUCTION}

Nonstarter lactic acid bacteria (NSLAB) are adventitious lactic acid bacteria that contaminate cheeses. The origin of NSLAB in cheese is probably the raw milk, as it has been shown that very small percentages of NSLAB may survive pasteurization and be the source of secondary flora in aseptic cheeses (Turner et al., 1986; Beresford et al., 2001). Alternatively, lactobacilli present in cheeses manufactured with pasteurized milk may be part of the resident flora in the dairy production plant (Naylor and Sharpe, 1958) and contaminate cheese milk after pasteurization (Martley and Crow, 1993; Somers et al., 2000).

Nonstarter lactic acid bacteria constitute the only main factor that remains uncontrolled in today's industrial cheese making, and consequently, they may be the main source of quality inconsistencies and defects in cheese products (Crow et al., 2001). The NSLAB counts can increase from a very low level (10 to $10^{4} \mathrm{cfu} / \mathrm{g}$ in 1 -d-old Cheddar cheese manufactured with pasteurized milk) up to $10^{7}$ to $10^{8} \mathrm{cfu} / \mathrm{g}$ during the first weeks of ripening, becoming dominant in cheese microbiota after starter decrease (Peterson and Marshall, 1990; Fox et al., 1998). The NSLAB are made up mainly of lactobacilli in cheeses manufactured with pasteurized milk, but may also include other lactic acid bacteria such as pediococci and enterococci, Streptoccocus thermophilus, and Leuconostoc spp. (Corsetti et al., 1998; Swearingen et al., 2001; Sánchez et al., 
2006). To date, no suitable method to obtain NSLABfree cheeses is available: aseptic cheese making is only appropriate for laboratory conditions and is not completely effective in keeping low levels of NSLAB during ripening (Kleter, 1977; McSweeney et al., 1994; Shakeel-Ur-Rehman et al., 2000c). On the other hand, the decrease in ripening temperature has been a successful approach to impair NSLAB growing, but with a concomitant slow down of the biochemical transformations involved in ripening (Shakeel-Ur-Rehman et al., 2000a,b). The alternative of indirectly controlling secondary microflora in cheese by means of the addition of an adjunct culture has been suggested (Crow et al., 2001; Di Cagno et al., 2003). For that purpose, a relatively important amount of research work has been committed to isolate and characterize strains of NSLAB from good quality cheeses. Most available strains have been obtained from Cheddar cheese (Crow et al., 2001; Swearingen et al., 2001; Banks and Williams, 2004), although recent studies are more diverse (De Angelis et al., 2001; Bude-Ugarte et al., 2006).

Overall, NSLAB grow poorly in milk, but they are able to grow in young cheeses (Stanley, 1998). They contribute to proteolysis in cheese mainly via their peptidolytic potential, increasing the amount of small peptides and free AA (Lynch et al., 1999). Some NSLAB have been also reported to possess key enzymes for cheese flavor formation by AA catabolism (Kieronczyk et al., 2003; Thage et al., 2005). The criteria that a nonstarter Lactobacillus strain should meet to become an appropriate adjunct culture include: to reach and maintain high levels of cell density during ripening, cause no defect in the product, and if possible, impact positively on cheese overall quality (Crow et al., 2001; Di Cagno et al., 2003). The influence of a given adjunct culture in different cheese models may differ because its growth and biochemical expression rely on the technology applied and the starter used (Thomas, 1987; Lane et al., 1997; Hynes et al., 2001b). In addition, some biochemical activities may be considered defective in one cheese but desirable in others [e.g., $\mathrm{CO}_{2}$ production, L-lactate isomerization, aldehyde production (Di Cagno et al., 2003)].

The objective of the present study was to assess the technological properties of nonstarter Lactobacillus strains isolated from Argentinean cheeses by means of in vitro and in situ studies. For that purpose, the strains were examined for proteolytic and acidifying activities, phage-resistance and tolerance to $\mathrm{NaCl}$ and $\mathrm{KCl}$. After that, 4 lactobacilli were selected and tested as adjunct cultures in soft and semihard cheeses.

\section{MATERIALS AND METHODS}

\section{Strains}

Twenty-three strains of nonstarter lactobacilli isolated from good quality soft and semihard Argentinean cheeses were assayed by in vitro tests. The strains belonged to the species Lactobacillus casei (7 strains), Lactobacillus rhamnosus (4 strains), L. plantarum (5 strains), L. curvatus (3 strains), Lactobacillus fermentum (2 strains), Lactobacillus delbrueckii ssp. lactis (1 strains), and Lactobacillus perolens (1 strain; Bude-Ugarte et al., 2006). For the characterization of proteolytic activity, the nonstarter lactobacilli were compared with other lactic acid bacteria: 2 strains of Strep. thermophilus identified as Mo11 and 5-C, from commercial starters (Binetti et al., 2007); one strain of Lactobacillus delbruecki ssp. bulgaricus (YSDY) and one strain of $L$. delbruecki ssp. lactis (Ab1), also from commercial cultures (Guglielmotti et al., 2006); and 3 strains of Lactobacillus helveticus (15807, SF209, and SF133), isolated from natural whey starter (Quiberoni et al., 1998).

\section{In Vitro Characterization}

Milk acidification kinetics, as well as proteolytic (ophthaldialdehyde spectrophotometric assay, OPA Test, Church et al., 1983) and acidifying activities were determined by inoculation $(2 \% \mathrm{vol} / \mathrm{vol})$ of the strains in sterile, reconstituted ( $10 \% \mathrm{wt} / \mathrm{vol})$, commercial, dry skim milk followed by incubation for $24 \mathrm{~h}$ at $34^{\circ} \mathrm{C}$. The $\mathrm{pH}$ values were measured with a model SA $720 \mathrm{pH}$ meter (Orion, Beverly, MA) and plotted against time. Proteolytic activities were expressed as the differences in absorbance at $340 \mathrm{~nm}\left(\mathrm{~A}_{340}\right)$ between strain cultures and a control of uninoculated milk. The acidity developed, measured by titration with $0.1 \mathrm{~N} \mathrm{NaOH}$, was expressed as percentage of lactic acid.

The fast or slow character of the strains was determined by inoculation $(2 \% \mathrm{vol} / \mathrm{vol})$ of strain cultures in milk, milk supplemented with $1 \%$ (wt/vol) glucose or with $0.25 \%$ (wt/vol) casein hydrolysate, and milk supplemented with both $1 \%$ glucose and $0.25 \%$ casein hydrolysate (McKay and Baldwin, 1974; Efstathio and McKay, 1976), followed by the assessment of $\mathrm{pH}$ after incubation by $24 \mathrm{~h}$ at $34^{\circ} \mathrm{C}$.

The fraction of milk cultures soluble in trichloroacetic acid 8\% wt/vol obtained for the OPA test was also analyzed by reverse phase HPLC. The HPLC equipment consisted of a quaternary pump, an inline degasser and UV/VIS detector, all Series 200, purchased from Perkin Elmer (Norwalk, CT). An interface module connected to a computer was used for acquisition of chromatographic data with the software Turbochrom (Perkin Elmer). A $220 \mathrm{~mm} \times 4.6 \mathrm{~mm}$ Aquapore OD$300 \mathrm{C} 18,7 \mu \mathrm{m}-300 \AA$ analytical column was used (Perkin Elmer). Samples were filtered through 0.45$\mu \mathrm{m}$ membranes (Millex, Millipore, Sao Paulo, Brazil), and $60 \mu \mathrm{L}$ was injected into the HPLC chromatograph. 
Detection was performed at $214 \mathrm{~nm}$, and column temperature was maintained at $40^{\circ} \mathrm{C}$. The gradient starting from $100 \%$ of solvent $\mathrm{A}\left(\mathrm{H}_{2} \mathrm{O}\right.$ :trifluoroacetic acid (TFA) $1,000: 1.1, \mathrm{vol} / \mathrm{vol}$ ) and $0 \%$ of solvent $\mathrm{B}$ (acetonitrile: $\mathrm{H}_{2} \mathrm{O}: \mathrm{TFA}$ 600:400:1, vol/vol) was generated 10 min after injection. The proportion of solvent $\mathrm{B}$ was increased by $1 \% / \mathrm{min}$ ( $80 \mathrm{~min}), 20 \% / \mathrm{min}$ ( $1 \mathrm{~min}$ ), $0 \% /$ $\min (4 \mathrm{~min})$, and then returned to starting conditions, which took $1 \mathrm{~min}$. These last setting conditions were maintained for 10 min (Hynes et al., 2003).

Lactobacillus casei strains were tested for cross sensitivity to bacteriophages using the Spot and Turbidity Tests, as described by Svensson and Christiansson (1991). The phages were two collection phages: lytic phage $\phi \mathrm{g} \mathrm{J}-1$ (sensitive strain L. casei ssp. casei ATCC 27139), and lytic phage $\phi$ gPL-1 (sensitive strain Lactobacillus paracasei ssp. paracasei ATCC 27092, and 4 phages isolated in INLAIN from faulty batches of fermented milks in dairy industry: $\phi$ gMLC-A (Capra et al., 2006), $\phi$ gMLC-B, $\phi$ gMLC-C, and $\phi$ gMLC-D.

Salt resistance was studied by inoculating strains in de Man, Rogosa, Sharpe (MRS) broth, which contained 1, 2, or $3 \%$ (wt/vol) $\mathrm{NaCl}$; $\mathrm{KCl}$ was also assayed in the same conditions, as it has been proposed to replace part of the $\mathrm{NaCl}$ in cheeses (Reddy and Marth, 1993). Cultures were incubated at $34^{\circ} \mathrm{C}$, and after 24 $\mathrm{h}$ cell growth $\left(\mathrm{A}_{560}\right)$ was measured and compared with a control without salt addition. The results were expressed as the percentage of growth in the presence of $\mathrm{NaCl}$ or $\mathrm{KCl}$ compared with the control.

\section{In Situ Characterization: Cheese Making Experiments}

Four strains were selected according to the results of in vitro tests and assayed individually as adjunct cultures in cheese making experiments at pilot plant scale. Cheese making experiments consisted of 2 trials; in the first one a soft cheese model was chosen (Cremoso Argentino cheese) and in the second trial a semihard cheese variety was assayed (Pategrás Argentino). Each trial was single block completely randomized, where cheese making days were subblocks. In both trials, control cheeses did not contain adjunct cultures but only a commercial starter composed of several strains of Strep. thermophilus. Experimental cheeses were made with the same starter plus a culture of the tested strain of Lactobacillus.

For both types of cheese, raw milk obtained from a nearby dairy factory (Milkaut S.A., Franck, Santa Fe, Argentina), was batch pasteurized at $65^{\circ} \mathrm{C}$ for $20 \mathrm{~min}$, and cooled to $37^{\circ} \mathrm{C}$. Calcium chloride (Merck, Darmstadt, Germany) was added to a final concentration of $0.02 \%$ (wt/vol) in the milk. After that, milk was divided in 4 aliquots of $40 \mathrm{~L}$ each and sent to cheese vats; 2 vats were used for Cremoso cheeses and the other 2 for Pategrás cheeses. A lyophilized culture of Strep. thermophilus (Chr. Hansen Argentina, Quilmes, Argentina) was used as primary starter; it was dispersed in approximately $100 \mathrm{~mL}$ of pasteurized milk and maintained for 5 to $10 \mathrm{~min}$ at $37^{\circ} \mathrm{C}$ before addition to cheese milk. After that, adjunct cultures were added in experimental cheeses. All the lactic bacteria (starter and adjunct) were added in a dose high enough to achieve $10^{6} \mathrm{cfu} / \mathrm{mL}$ in cheese milk. After $15 \mathrm{~min}, 1 \mathrm{~g}$ of chymosin produced by fermentation of genetically modified Kluyveromyces lactis (Maxiren 150, Gist Brocades, France) was dispersed in $25 \mathrm{~mL}$ of distilled water and added into each vat.

In Cremoso cheeses, coagulation took place at $37^{\circ} \mathrm{C}$. When the coagulum strengthened to the typical consistency of this enzymatic curd, it was cut to gross cubes of approximately $2 \mathrm{~cm}^{3}$. The curd grains were then gently stirred in the whey to allow light whey drainage, but without ulterior cutting of curd particles. This step was finished after 10 to $15 \mathrm{~min}$, and then the curd was allowed to set in the bottom of the vat. Whey was pumped out and the curd was put in the mold. Before salting, the curd was placed in a hot chamber $\left(40^{\circ} \mathrm{C}\right)$ until a pH value within the range of 5.2 to 5.3 was reached. Salting was performed by immersion in brine (20\% wt/vol, $\mathrm{pH} 5.4$ ) at $5^{\circ} \mathrm{C}$ for $4 \mathrm{~h}$, to stop the starter activity. A 4-kg cheese was obtained from each vat. The cheeses were vacuum packed in plastic bags and ripened at $5^{\circ} \mathrm{C}\left( \pm 0.5^{\circ} \mathrm{C}\right)$ for $60 \mathrm{~d}$ (Hynes et al., 2001a).

As for Pategrás cheese, the coagulation step was performed at a somewhat lower temperature: $35^{\circ} \mathrm{C}$. When the curd reached the appropriated strength, it was cut in successive steps (with manual stirring between steps) until it reached the size of a corn grain, maintaining temperature about $35^{\circ} \mathrm{C}$. The cuttingstirring step took 20 min approximately. The curd grains and the whey were then gently stirred and heated at the rate of $0.5^{\circ} \mathrm{C} / \mathrm{min}$ until $45^{\circ} \mathrm{C}$ then maintained for 10 to $15 \mathrm{~min}$ approximately to reduce the moisture content of curd grains. After that, the curd was separated from whey and molded. The two molds obtained from the 2 vats were piled and pressed during $24 \mathrm{~h}\left(0.2\right.$ to $\left.0.3 \mathrm{~kg} \mathrm{~cm}^{2}\right)$. Young cheeses were brined in $20 \%(\mathrm{wt} / \mathrm{vol}$ ) $\mathrm{pH} 5.4$ brine for $24 \mathrm{~h}$ and ripened for 60 $\mathrm{d}$ at $12^{\circ} \mathrm{C}\left( \pm 0.5^{\circ} \mathrm{C}\right)$ and $80 \%$ relative humidity (Bergamini et al., 2006).

Gross composition, pH, microbiology, and overall quality of the cheeses were assessed. Gross composition was determined in 3-d-old cheeses, whereas $\mathrm{pH}$ was monitored during Cremoso cheese making and during ripening of all cheeses. Curves of $\mathrm{pH}$ were not obtained for Pategrás cheese making as the procedure 
for this cheese variety does not imply a curd acidification (cheddaring) step. Dry matter was analyzed by drying the sample at $105 \pm 1^{\circ} \mathrm{C}$ until constant weight according to IDF standards (IDF, 1982). Fat matter was quantified by a butyrometric method (IDF, 1997) and $\mathrm{pH}$ was assessed according to the American Public Health Association standard (Bradley et al., 1993). Protein content was determined by the Kjeldahl method according to IDF standards (IDF, 1993). For microbial counts, five to ten 10 -g cylinders were taken from the cheeses with a sterile sampler and ground aseptically. Then, a 20-g sample was homogenized for $3 \mathrm{~min}$ in a stomacher lab blender (PBI International, Milan, Italy) with sterile sodium citrate solution ( $2 \%$ wt/vol). From cheese homogenates, decimal dilutions were made in $0.1 \%$ (wt/vol) sterile peptone water. For lactobacilli adjunct cultures and NSLAB, counts were performed on MRS-Agar after evaluation of a set of different culture media, which demonstrated that recuperation on MRS was the best and that the starter strain colonies did not interfere (Bude-Ugarte et al., 2006). Tested media were MRS agar (Biokar, Beauvais, France), bile-MRS agar (Vinderola and Reinheimer, 2000) acid-MRS agar (pH 5.5) (IDF, 1988), and Elliker agar $\mathrm{NaCl}(6.5 \% \mathrm{NaCl} w \mathrm{w} / \mathrm{vol}$; Biokar) for lactobacilli. Surface plating was made, and the plates were incubated for $48 \mathrm{~h}$ at $34^{\circ} \mathrm{C}$. Lactic acid starter bacteria (Strep. thermophilus) were enumerated on skim milk agar $\left(48 \mathrm{~h}\right.$ at $\left.37^{\circ} \mathrm{C}\right)$.

Overall quality of the cheeses was evaluated by 3 independent experienced graders. The overall quality of cheese samples involved the evaluation of flavor acceptability and texture acceptability and was scored using a 0 to 8 point scale (0-1: unacceptable, $2-3$ : substandard, 4-5: standard, 6-7: good, and 8: excellent; Lynch et al., 1996).

\section{Statistics}

The results of compositional analyses of the cheeses were compared by 1-way ANOVA. Posthoc LSD test was applied to detect groups of mean values (Statistix 8, Analytical Software, Tallahassee, FL).

Principal components analysis (PCA) was applied to the peptide maps of soluble fraction in $8 \%$ trichloroacetic acid, to reduce dimensionality, compare chromatograms objectively, and detect subjacent structures in the data ensemble. The areas of peaks expressed on arbitrary units were considered as independent variables for PCA, with standardization to a mean of zero and their original variances (covariance matrix; Bergamini et al., 2006). Multivariate analysis was performed with the software Unscrambler 7.6 (CAMO ASA, Oslo, Norway).

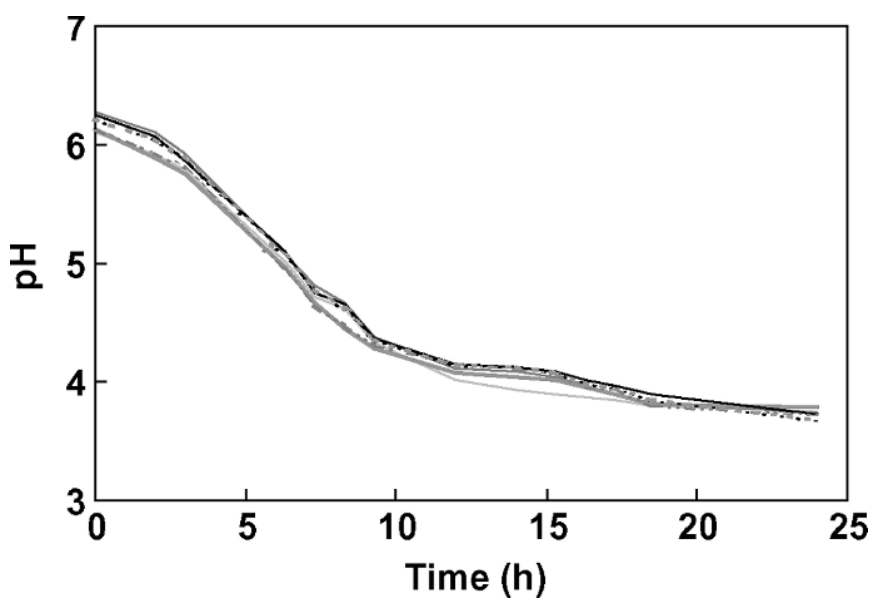

Figure 1. Milk acidification kinetics. (-----) Lactobacillus plantarum I33, (---) Lactobacillus rhamnosus I75, (-) L. plantarum I87, (-•---) L. rhamnosus I78, (----) Lactobacillus curvatus I48, (-), Lactobacillus delbrueckii ssp. lactis I92, (-) L. rhamnosus I73.

\section{RESULTS}

\section{In Vitro Characterization}

The strains were classified as fast or slow according to the final $\mathrm{pH}$ values reached by their milk cultures after $24 \mathrm{~h}$ at $34^{\circ} \mathrm{C}$. Only 7 strains (30\%) were classified as fast, cultures of which had a final $\mathrm{pH}$ value of 3.73 \pm 0.03 . Milk acidification kinetics of fast strains are shown in Figure 1. The other strains were slow in which case cultures only reached pH $5.78 \pm 0.19$. Fast strains were $L$. rhamnosus (3 strains), L. curvatus (1 strain), L. plantarum (2 strains), and L. delbrueckii ssp. lactis (1 strain). Average acidifying and proteolytic activities of fast strains were $1.33 \pm 0.03 \%$ lactic acid and $\mathrm{A}_{340} 0.19 \pm 0.03$, respectively.

Some of the slow strains were able to coagulate milk and decreased $\mathrm{pH}$ significantly ( $\alpha=0.05)$, similarly to fast strains, when cultured in milk supplemented with casein hydrolysate, glucose, or both. This group represented $44 \%$ of the slow strains (7 strains) and was mainly composed of $L$. casei strains (4 strains), but also by strains of $L$. perolens (1), L. plantarum (1), and L. rhamnosus (1). The rest of the strains did not grow in milk when it was enriched with casein hydrolysate or glucose, not even when it was inoculated with both. This group of strains consisted of $L$. casei (3), L. curvatus (2), L. fermentum (1), and L. plantarum (2) strains.

The proteolytic activity of the strains assayed was low or moderate, taking into account the comparative activities of the other lactic acid bacteria assayed in the same conditions. The average value was $\mathrm{A}_{340} 0.18$ \pm 0.02 for NSLAB strains, whereas $A_{340}$ ranged from 0.02 for Strep. thermophilus 5-C to 0.83 for L. helveticus SF209. 
a)



b)

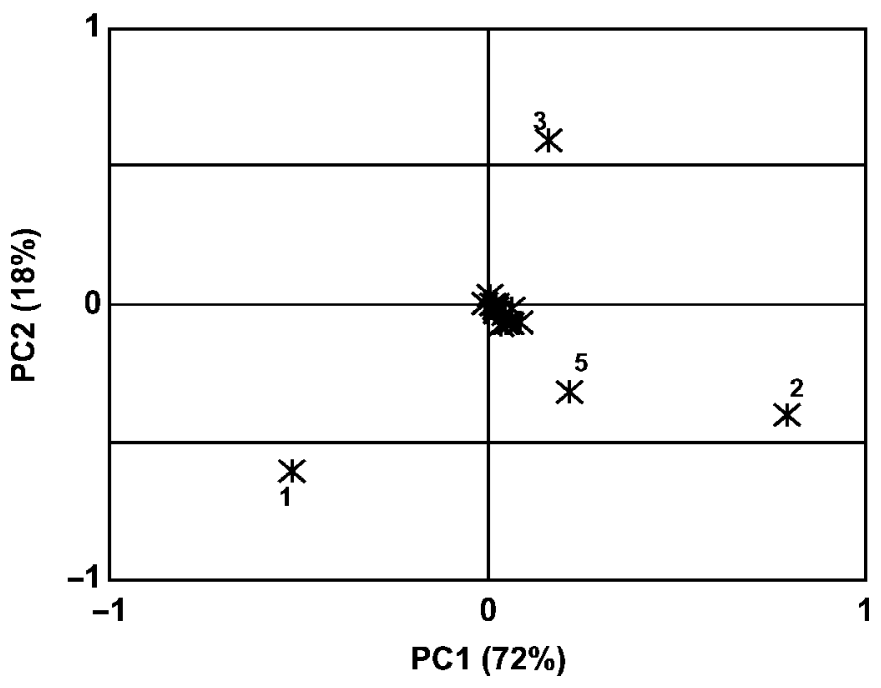

Figure 2. Principal components analysis of reverse-phase-HPLC profiles of the soluble fraction in trichloroacetic acid 8\% wt/vol of milk cultures of fast nonstarter lactobacilli (NSLAB) strains and other lactic acid bacteria assayed in the same conditions: a) score plot. NSLAB33, NSLAB75, NSLAB87, NSLAB78, NSLAB48, NSLAB92, and NSLAB73: Lactobacillus plantarum I33, Lactobacillus rhamnosus I75, L. plantarum I87, L. rhamnosus I78, Lactobacillus curvatus I48, Lactobacillus delbrueckii ssp. lactis I92 and L. rhamnosus I73, respectively. Lh15807, LhSF133, and LhSF209: Lactobacillus helveticus isolated from whey starters, LlAb1 and LbYSDY: L. delbrueckii ssp. lactis and Lactobacillus delbrueckii ssp. bulgaricus from commercial starters, StMo11 and St5-C: Streptococcus thermophilus from commercial starters. b) Loading plot: the variables (peaks of the chromatogram) with highest influence on principal components 1 and 2 (PC1 and PC2) are labeled with characters 1, 2, 3 and 5 in increasing order of retention time. Peaks with low impact on PC1 and $\mathrm{PC} 2$ are not labeled.

As for PCA results (Figure 2), the peptide profiles of NSLAB cultures were grouped together on the score plot of the first vs. the second principal components
(PC1 and PC2), occupying the quarter of the chart defined by positive values of PC1 and PC2, as well as other moderately proteolytic lactic acid bacteria assayed in the same test. The peptide maps corresponding to the most proteolytic strains, which were tested in the same conditions, differed from NSLAB profiles, both in the amount and area of the peaks, and were plotted separately, in the quarter of the graph defined by positive values of PC1 and negative values of PC2. The Strep. thermophilus strains, which were weakly proteolytic, were also grouped apart, in the opposite quarter of the chart (Figure 2a). The impact of different peaks from the peptide profile on PC1 and PC2 is shown in Figure 2b: only 4 peaks showed high influence, whereas the rest had a low impact. The former eluted early during chromatography: they probably represent hydrophilic oligopeptides.

All the strains assayed were resistant to $\mathrm{NaCl}$ and $\mathrm{KCl}$, the later showing the weakest inhibitory effect. Most strains were able to grow in the presence of $1 \%$ of $\mathrm{NaCl}$ or $\mathrm{KCl}$ to the same extent as in the control without salt (Figure 3a). When $\mathrm{NaCl}$ or $\mathrm{KCl}$ concentration was increased to 2 or $3 \%$, the proportion of the strains that grew as much as in the control diminished; however, all the strains assayed showed significant growth in the tested conditions (Figure $3 \mathrm{~b}$ and $3 \mathrm{c}$ ). No sensitive strains were found among the nonstarter $L$. casei strains, for the 6 bacteriophages tested.

Taking into account the results of in vitro characterization, 4 strains of lactobacilli were selected for cheese making experiments. Previous studies about the probiotic potentiality of these isolates were also considered (Bude-Ugarte et al., 2006). Among the isolates with the best probiotic and biological properties, 3 slow strains were chosen, to minimize their contribution to acidification during cheese making; they were $L$. rhamnosus I77, L. casei I90, and L. plantarum I91. One of the fast strains, L. rhamnosus I73, was also selected because it showed interesting probiotic features (Bude-Ugarte et al., 2006).

\section{In Situ Characterization: Cheese Making Experiments}

Primary starter was about $10^{8} \mathrm{cfu} / \mathrm{g}$ in curd samples at molding and $10^{9} \mathrm{cfu} / \mathrm{g}$ in cheeses after brining. This last level remained more or less constant during ripening of Cremoso cheeses. In Pategrás cheeses, the starter population decreased slightly during ripening. Primary starter counts were similar in control and experimental cheeses in Cremoso and Pategrás cheese varieties (Figures 4 and 5).

On the other hand, the adjunct culture remained viable during all ripening at levels of $10^{7}-10^{8} \mathrm{cfu} / \mathrm{g}$ in 

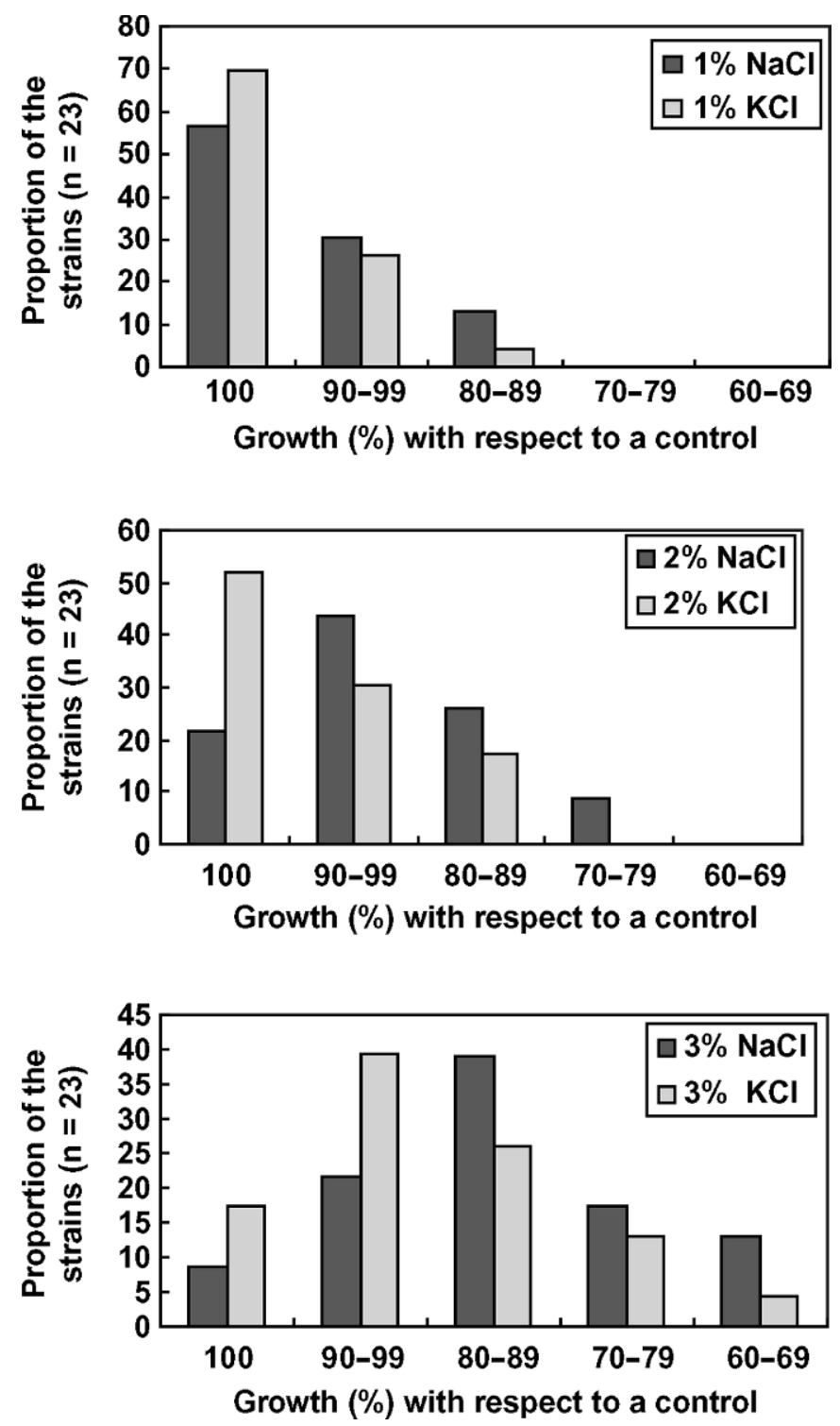

Figure 3. Proportion of strains of nonstarter lactobacilli resistant to increasing concentrations of $\mathrm{NaCl}$ and $\mathrm{KCl}$.

Cremoso cheeses. The adjunct culture population for the strains $L$. casei 190 and L. rhamnosus I77 was more or less constant in Cremoso cheeses during 60 $\mathrm{d}$, whereas L. rhamnosus I73 increased during the first $15 \mathrm{~d}$ and then tended to decrease. The $L$. plantarum I91 increased up to $10^{8} \mathrm{cfu} / \mathrm{g}$ in the first $15 \mathrm{~d}$ and then remained constant over the rest of the ripening period (Figure 4). The NSLAB level in Cremoso cheeses without added lactobacilli (control cheeses) was always under $10^{5} \mathrm{cfu} / \mathrm{g}$ (results not shown).

As for Pategrás cheeses, adjunct lactobacilli rapidly increased from $10^{7} \mathrm{cfu} / \mathrm{g}$ in curd up to $10^{8}-10^{9}$ in 7 -dold cheeses. The L casei 190 population reached $10^{9}$

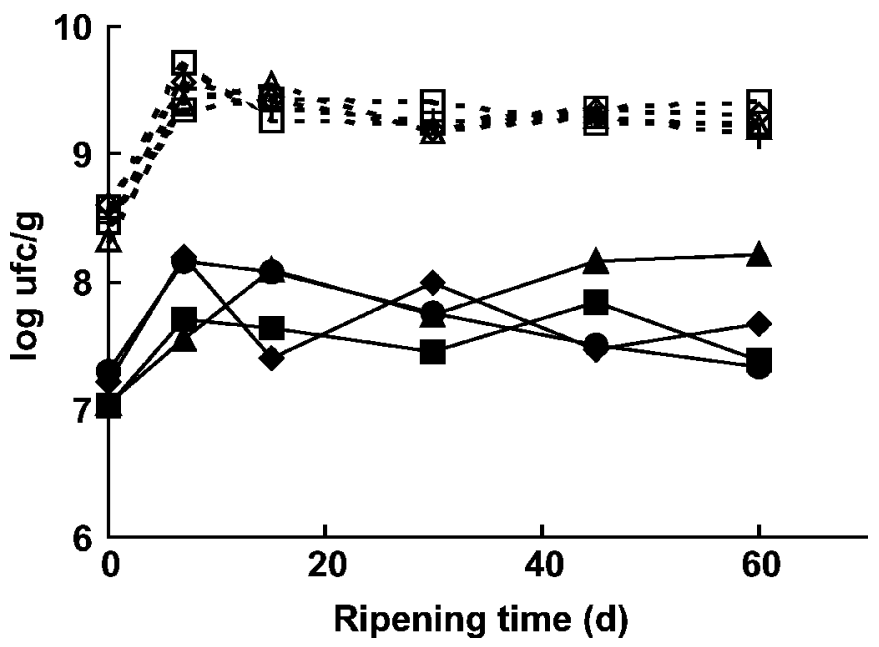

Figure 4. Population of starter streptococci (dotted lines, open symbols) and adjunct lactobacilli (solid lines and symbols) in Cremoso cheeses during ripening. Symbols: +: control cheeses (streptococci); $\bigcirc$, ๑: cheeses with Lactobacillus rhamnosus I73; $\diamond, \diamond:$ L. rhamnosus I77; $\square, \mathbf{\square}$ : Lactobacillus casei $90, \triangle, \mathbf{\Delta}$ : Lactobacillus plantarum I91. Nonstarter lactobacilli in control cheeses remained always below $10^{5}$ UFC/g and are not shown.

cfu/g in $7 \mathrm{~d}$ and then remained constant at a level that equaled the starter culture population. The $L$. plantarum I91 and L. rhamnosus I77 and I73 also attempted populations similar to that of the starter, but after the first month of ripening. The NSLAB in Pategrás cheeses without added lactobacilli augmented up to $10^{6} \mathrm{cfu} / \mathrm{g}$ in $7 \mathrm{~d}$ of ripening and reached $10^{8}$ in 15-d-old cheeses (Figure 5).



Figure 5. Population of starter streptococci (dotted lines, open symbols) and adjunct or nonstarter lactobacilli (solid lines and symbols) in Pategrás cheeses during ripening. Symbols:,$+ \times$ control cheeses; $\bigcirc$, О: cheeses with Lactobacillus rhamnosus I73; $\diamond, \diamond: L$. rhamnosus I77; $\square$, $\mathbf{\square}$ : Lactobacillus casei $90 ; \triangle$, $\mathbf{\Delta}$ : Lactobacillus plantarum $\mathrm{I} 91$. 


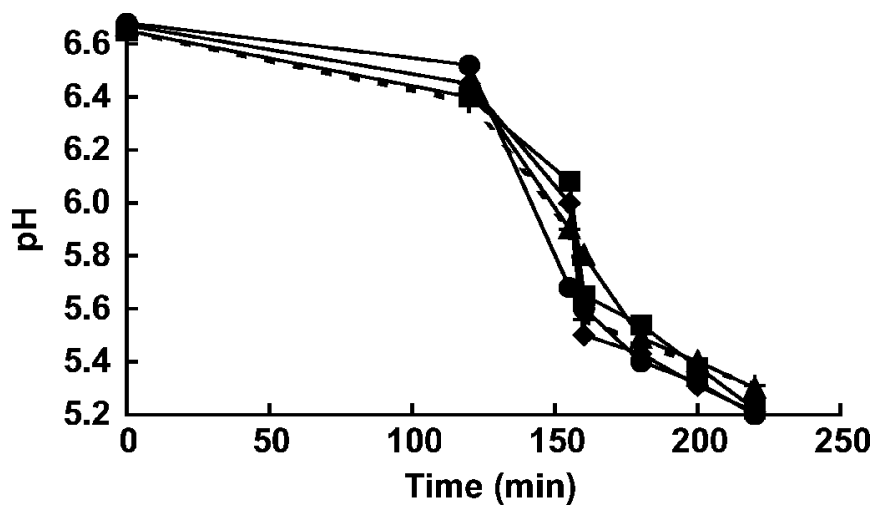

Figure 6. Acidification curves for Cremoso cheese makings with a starter of Streptococcus thermophilus (control cheeses, +) plus an adjunct culture of Lactobacillus rhamnosus $73(\bullet)$, L. rhamnosus 77

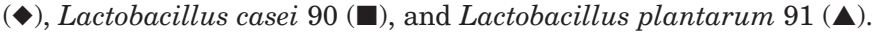

The evolution of $\mathrm{pH}$ during Cremoso cheese makings was similar in control and experimental cheeses with adjunct cultures of $L$. casei $\mathrm{I} 90$ and $L$. plantarum I91. On the contrary, experimental cheeses that included L. rhamnosus strains showed an increased rate of acidification during the incubation step in the hot chamber, before salting (Figure 6).

Gross composition did not significantly differ among the 5 types of cheeses manufactured, except for moisture content of Cremoso cheeses with $L$. rhamnosus I73, which also showed significant post acidification during ripening. Cremoso and Pategrás cheeses with L. rhamnosus $\mathrm{I} 77$ also had a significant lower $\mathrm{pH}$ value at the end of the ripening, even if the adjunct culture was a slow strain (Table 1).

All Pategrás cheeses, with and without lactobacilli adjunct cultures, were considered good by the graders, with scores ranges between 5.9 and 7.2. Cremoso cheeses with the lowest $\mathrm{pH}$ values, which contained L. rhamnosus adjunct cultures, were scored standard or substandard; the rest of the Cremoso cheeses were classified good and excellent (Table 2).

\section{DISCUSSION}

Most of the tested lactobacilli were unable to coagulate milk, and were classified as slow strains. Even when casein hydrolysate and glucose were added, an important proportion of the strains were unable to grow in reconstituted skim milk. The result is not surprising because lactobacilli of NSLAB origin usually do not grow well in milk, but they are able to attempt high counts in cheese after a few weeks of ripening (Peterson and Marshall, 1990; Stanley, 1998; Banks and Williams, 2004). This trend was confirmed by cheese making experiments; even slow strains devel- oped up to high levels in the 2 types of cheeses studied, soft Cremoso Argentino cheese and semihard Pategrás cheese.

The fact that most of the tested strains were not able to coagulate milk is not a drawback for their use as adjunct cultures in cheese making because secondary lactic cultures need not significantly contribute to acidification during cheese making. In fact, excessively high acidifying activity can cause curd over acidification and change the moisture content of the cheese (Crow et al., 2001). Highly acidifying nonstarter lactobacilli strains may be evaluated for mixed primary starter cultures; L. plantarum and $L$. casei isolates have been assayed as a part of mixed starters in several cheese varieties (Mendia et al., 2000; Macedo et al., 2004; Herreros et al., 2007).

Proteolytic activity, on the contrary, is an interesting property for all, adjunct or primary cheese starters as proteolysis and peptidolysis during cheese ripening can influence the background flavor of the product, and provide most of the precursors of cheese aroma (Yvon, 2006). Among the tested strains, fast lactobacilli showed moderate proteolytic and peptidolytic activities compared with other lactic acid bacteria, such as L. helveticus SF209, which is highly proteolytic and peptydolitic in vitro and in cheese (Quiberoni et al., 1998; Hynes et al., 2003), and Strep. thermophilus 5$\mathrm{C}$, which scarcely shows any proteolytic activity (Binetti et al., 2007). Several peptidases have been identified in nonstarter lactobacilli of the species $L$. plantarum and the L. casei group, including aminopeptidases, dipeptidases, and peptidases for prolinecontaining peptides (Williams and Banks, 1997; Martınez-Cuesta et al., 2001). Even if no carboxypeptidase' has been purified from lactic acid bacteria yet, carboxypeptidase activity was detected in nonstarter lactobacilli (Macedo et al., 2000). Peptidolytic activities in NSLAB are species- and strain- dependent and rely on the growing conditions of the culture and the physiological state of the cells (Williams et al., 2002). Because fast strains showed similar proteolytic activities and produced equivalent peptide profiles that other lactic acid bacteria already tested in cheese with positive results (Hynes et al., 2003), it can be expected that they will have a favorable influence in peptide breakdown during cheese ripening.

Rotation of starter cultures is a common strategy in dairy industry to control phage proliferation and prevent fermentation failures (Moineau and Lévesque, 2005). A relatively large choice of primary starters is available for this purpose, but secondary cultures such as adjunct or probiotic lactobacilli do not offer as many possibilities because available strains are still few (Capra et al., 2006). In this work, we have found that all 
Table 1. Gross composition and $\mathrm{pH}$ of 3-d-old soft and semihard cheeses obtained with and without an adjunct culture of Lactobacillus

\begin{tabular}{|c|c|c|c|c|c|}
\hline & \multicolumn{5}{|c|}{ Type of cheese ${ }^{1}$} \\
\hline & $\mathrm{CC}$ & CLrI73 & CLrI77 & CLcI90 & CLpI91 \\
\hline Moisture & $52.12 \pm 0.92^{\mathrm{a}}$ & $49.75 \pm 0.90^{\mathrm{b}}$ & $49.9 \pm 1.05^{\mathrm{b}}$ & $53.76 \pm 1.93^{\mathrm{a}}$ & $52.44 \pm 1.35^{\mathrm{a}}$ \\
\hline Protein content & $18.34 \pm 0.65$ & $19.35 \pm 1.09$ & $18.98 \pm 0.45$ & $18.54 \pm 0.32$ & $19.18 \pm 0.70$ \\
\hline \multirow[t]{2}{*}{ Fat matter } & $23.70 \pm 2.10$ & $24.80 \pm 1.96$ & $25.14 \pm 3.20$ & $23.70 \pm 1.82$ & $24.18 \pm 2.05$ \\
\hline & $\mathrm{PC}$ & PLrI73 & PLrI77 & PLcI90 & PLpI91 \\
\hline Moisture & $40.77 \pm 1.12$ & $41.55 \pm 1.39$ & $41.47 \pm 0.89$ & $40.63 \pm 1.35$ & $41.35 \pm 0.80$ \\
\hline Protein content & $23.32 \pm 0.50$ & $23.31 \pm 1.08$ & $23.53 \pm 0.61$ & $23.69 \pm 1.14$ & $22.97 \pm 0.49$ \\
\hline Fat matter & $31.60 \pm 2.23$ & $29.7 \pm 2.02$ & $32.32 \pm 3.24$ & $31.00 \pm 1.14$ & $30.86 \pm 2.02$ \\
\hline \multirow[t]{5}{*}{ Ripening time (d) } & $\mathrm{CC}$ & CLrI73 & CLrI77 & CLcI90 & CLpI91 \\
\hline & $5.10 \pm 0.10$ & $5.20 \pm 0.14$ & $5.15 \pm 0.08$ & $5.08 \pm 0.16$ & $5.13 \pm 0.07$ \\
\hline & $5.20 \pm 0.12$ & $5.05 \pm 0.10$ & $5.05 \pm 0.17$ & $5.10 \pm 0.09$ & $5.15 \pm 0.06$ \\
\hline & $5.18 \pm 0.10^{\mathrm{a}}$ & $4.90 \pm 0.06^{\mathrm{b}}$ & $4.90 \pm 0.09^{\mathrm{b}}$ & $5.02 \pm 0.16^{\mathrm{ab}}$ & $5.10 \pm 0.07^{\mathrm{a}}$ \\
\hline & $\mathrm{PC}$ & PLrI73 & PLrI77 & PLcI90 & PLpI91 \\
\hline 7 & $5.20 \pm 0.07$ & $5.18 \pm 0.18$ & $5.10 \pm 0.10$ & $5.20 \pm 0.04$ & $5.05 \pm 0.08$ \\
\hline 30 & $5.15 \pm 0.14$ & $5.20 \pm 0.14$ & $5.08 \pm 0.06$ & $5.00 \pm 0.10$ & $4.98 \pm 0.18$ \\
\hline 60 & $5.10 \pm 0.15^{\mathrm{a}}$ & $5.08 \pm 0.10^{\mathrm{a}}$ & $4.90 \pm 0.06^{\mathrm{b}}$ & $5.13 \pm 0.8^{\mathrm{a}}$ & $5.08 \pm 0.13^{\mathrm{a}}$ \\
\hline
\end{tabular}

${ }^{\mathrm{a}, \mathrm{b}}$ Means in a row with different superscripts differ $(\alpha=0.05)$.

${ }^{1}$ CC: Cremoso cheese without an adjunct culture (control), CLrI73, CLrI77, CLcI90, CLpI91: Cremoso cheese with an adjunct culture of Lactobacillus rhamnosus I73, L. rhamnosus I77, Lactobacillus casei I90, or Lactobacillus plantarum I91, respectively; PC: Pategrás cheese without an adjunct culture (control), PLrI73, PLrI77, PLcI90, PLpI91: Pategrás cheeses with an adjunct culture of L. rhamnosus I73, L. rhamnosus I77, L. casei $\mathrm{I} 90$, or L. plantarum I91, respectively.

the $L$. casei strains were resistant to phages specific of $L$. casei and $L$. paracasei, both from collections or isolated from Argentinean dairy plants during infection episodes. This characteristic constitutes a promising feature of the tested bacteria, especially taking into account that several strains in the same set of lactobacilli have shown probiotic potential (BudeUgarte et al., 2006).

Table 2. Overall quality ${ }^{1}$ of soft and semihard cheeses obtained with and without an adjunct culture of Lactobacillus

\begin{tabular}{lcccc}
\hline \multicolumn{5}{c}{ Type of cheese $^{2}$} \\
\hline CC & CLrI73 & CLrI77 & CLcI90 & CLpI91 \\
\hline $7.0 \pm 0.5$ & $4.0 \pm 0.7$ & $3.2 \pm 0.4$ & $7.1 \pm 0.3$ & $7.9 \pm 0.3$ \\
PC & PLrI73 & PLrI77 & PLcI90 & PLpI91 \\
\hline $6.7 \pm 0.7$ & $5.9 \pm 0.3$ & $5.9 \pm 0.3$ & $6.9 \pm 0.6$ & $7.2 \pm 0.4$ \\
\hline
\end{tabular}

${ }^{1}$ Scale: 0-1: unacceptable, 2-3: substandard, 4-5: standard, 6-7: good, and 8: excellent.

${ }^{2}$ CC: Cremoso cheese without an adjunct culture (control), CLrI73, CLrI77, CLcI90, CLpI91: Cremoso cheese with an adjunct culture of Lactobacillus rhamnosus I73, Lactobacillus rhamnosus I77, Lactobacillus casei I90, or Lactobacillus plantarum I91, respectively; PC: Pategrás cheese without an adjunct culture (control), PLrI73, PLrI77, PLcI90, PLpI91: Pategrás cheeses with an adjunct culture of $L$. rhamnosus I73, L. rhamnosus I77, L. casei I90, or L. plantarum I91, respectively.
Not surprisingly, all the assayed strains were resistant to $\mathrm{NaCl}$ and $\mathrm{KCl}$ in concentrations compatible with those usually found in cheeses, which is consistent with the fact that these strains have been isolated from cheeses and are probably adapted to such environmental conditions. The NSLAB have been reported as more salt tolerant than starter lactic acid bacteria (Fox et al., 1993), but this characteristic depends on the species and the strain of the starter (Lane et al., 1997). Resistance to salt is an evident technological requisite for cheese cultures.

All the lactobacilli cultures tested in cheese making experiments reached high levels in the cheeses during the first $24 \mathrm{~h}$ after manufacture and remained more or less constant during $60 \mathrm{~d}$ of ripening. This result indicates that the lactobacilli studied were able to proliferate in the cheese, although most of them had not been able to grow in milk. This is in agreement with previous reports on the subject (Stanley, 1998; Crow et al., 2001). In cheese, energy source for nonstarter lactobacilli remains unclear (Thomas, 1987; Williams et al., 2000; Beresford et al., 2001), whereas their nitrogen nutritional requirements are probably fulfilled by peptides and free amino acids derived from the proteolytic activity of the primary starter (Lane et al., 1997; Hynes et al., 2001b; Di Cagno et al., 2003). 
In control cheeses without added lactobacilli, NSLAB attained high numbers after $15 \mathrm{~d}$ in Pategrás cheese, but remained below $10^{5} \mathrm{cfu} / \mathrm{g}$ until the end of ripening in Cremoso cheese. Similar lactobacilli counts were found in semihard Argentinean cheeses, whereas soft cheeses from industrial environment showed a somewhat higher level of NSLAB (Bude-Ugarte et al., 2006). The difference in NSLAB development in both cheese models is probably due to the different ripening temperature (Shakeel-Ur-Rehman et al., 2000a).

The $2 L$. rhamnosus strains did not perform as well as adjunct cultures than $L$. casei $\mathrm{I} 90$ and $L$. plantarum I91, especially in the soft cheese model. These cultures modified the $\mathrm{pH}$ curve during curd cheddaring in Cremoso cheese making, which resulted in lower $\mathrm{pH}$ and increased DM in the product. These changes were verified for the 2 tested $L$. rhamnosus, although one of the strains had been classified as fast (L. rhamnosus I73) and the other, slow (L rhamnosus I77). In Pategrás cheese, only L. rhamnosus I77 caused significant decrease of $\mathrm{pH}$ toward the end of the ripening, and gross composition was not altered by the acidifying activity of the adjunct cultures. The L. rhamnosus 77 was not expected to be an over-acidifying adjunct culture because it was classified as a slow strain according to its ability to grow in milk. In cheeses, the existence of other lactic cultures in the food ecosystem, and the higher availability of oligopeptides and free amino acids, probably favored the growing of the adjunct culture, although information about NSLAB growing in cheese, especially concerning energy source, is still lacking.

Adjunct lactobacilli added to cheese both to improve the control over NSLAB adventitious flora or as probiotic cultures are required not to impact negatively on quality and, if possible, to improve sensory characteristics of the products (Crow et al., 2001; Bergamini et al., 2006). Some cultures of lactobacilli have been reported to produce cheeses more intensely flavored than controls, although aroma and flavor were not always improved (McSweeney et al., 1994; Lynch et al., 1999). In this study, the sensory quality of cheeses was generally considered good, except for Cremoso cheeses with $L$. rhamnosus that received lower scores, probably because low $\mathrm{pH}$ impacts significantly in soft cheese texture (Hynes et al., 1999). Cremoso cheeses with $L$. plantarum I91 and $L$. casei $\mathrm{I} 90$ were the best scored; similar results were found for one of these strains in miniature Cremoso cheeses (Mercanti et al., 2006).

In the present work, a group of nonstarter lactobacilli strains has been studied by focusing on their technological characteristics. The majority of the strains have shown promising technological properties, such as resistance to phage infections and tolerance to salts. In addition, several strains were able to coagulate milk and evidenced diverse proteolytic and peptidolytic activities. In cheeses, all the assayed lactobacilli reached high levels and survived during ripening. The $L$. casei I90 and $L$. plantarum I91 were appropriate for their use as adjunct cultures in both soft and semihard cheeses because they did not alter the composition of the products and improved their sensory attributes, whereas the L. rhamnosus strains tested were only suitable for the semihard cheese model. The impact of these strains in proteolysis and sensory profile of the cheeses will be the object of further study.

\section{ACKNOWLEDGMENTS}

The authors thank Mario Candioti and Diego Mercanti of Instituto de Lactologia Industrial for cheese making. This study was granted by PICTO 09-13227 BID 1728 OC/AR UNL, and ANPCyT, Argentina.

\section{REFERENCES}

Banks, J. M., and A. G. Williams. 2004. The role of the non-starter lactic acid bacteria in Cheddar cheese ripening. Int. J. Dairy Technol. 57:145-152.

Beresford, T. P., N. A. Fitzsimons, N. L. Brennan, and T. M. Cogan. 2001. Recent advances in cheese microbiology. Int. Dairy J. 11:259-274.

Bergamini, C. V., E. Hynes, and C. A. Zalazar. 2006. Proteolysis patterns in a probiotic semihard cheese. Int. Dairy J. 16:856866.

Binetti, A. G., N. B. Bailo, and J. A. Reinheimer. 2007. Spontaneous phage-resistant mutants of Streptococcus thermophilus: Isolation and technological characteristics. Int. Dairy J. 17:343-349.

Bradley, R. L., Jr., E. Arnold, Jr., D. M. Barbano, R. G. Semerad, D. E. Smith, and B. K. Vines. 1993. Chemical and physical methods. Pages 433-531 in Standard Methods for the Examination of Dairy Products. R. Marshall, ed. Am. Public Health Assoc., Washington, DC.

Bude-Ugarte, M., D. Guglielmotti, G. Giraffa, J. A. Reinhemer, and E. Hynes. 2006. Nonstarter lactobacilli isolated from soft and semihard argentinean cheeses: Genetic characterization and resistance to biological barriers. J. Food Prot. 69:2983-2991.

Capra, M. L., A. Quiberoni, H.-W. Ackermann, S. Moineau, and J. A. Reinheimer. 2006. Characterization of a New Virulent Phage (MLC-A) of Lactobacillus paracasei. J. Dairy Sci. 89:2414-2423.

Church, F. C., H. E. Swaisgood, D. H. Porter, and G. L. Catignain. 1983. Spectrophometric assay using o-phthaldialdehyde for determination of proteolysis in milk and isolated milk proteins. J. Dairy Sci. 66:1219-1227.

Corsetti, A., M. Gobetti, E. Smacchi, M. De Angelis, and J. Rossi. 1998. Accelerated ripening of Pecorino Umbro cheese. J. Dairy Res. 65:631-642.

Crow, V. L., B. Curry, and M. Hayes. 2001. The ecology of nonstarter lactic acid bacteria (NSLAB) and their use as adjuncts in New Zealand Cheddar. Int. Dairy J. 11:275-283.

De Angelis, M., A. Corsetti, N. Tosti, J. Rossi, M. R. Corbo, and M. Gobbetti. 2001. Characterization of non-starter lactic acid bacteria from italian ewe cheeses based on phenotypic, genotypic, and cell wall protein analyses. Appl. Environ. Microbiol. 67:2011-2020.

Di Cagno, R., M. De Angelis, V. Upadhyay, P. L. H. McSweeney, F. Minervini, G. Gallo, and M. Gobbetti. 2003. Effect of proteinases 
of starter bacteria on the growth and proteolytic activity of Lactobacillus plantarum DPC2741. Int. Dairy J. 13:145-157.

Efstathio, J. D., and L. L. McKay. 1976. Plasmids in Streptococcus thermophilus. Evidence that lactose metabolism and proteinase activity are plasmid linked. Appl. Environ. Microbiol. 32:38-44.

Fox, P. F., J. Law, P. L. H. McSweeney, and J. Wallace. 1993. Biochemistry of Cheese Ripening. Pages 389-438 in Cheese: Chemistry, Physics and Microbiology. Vol. 1. P. F. Fox, ed. Chapman \& Hall, London, UK.

Fox, P. F., P. L. H. McSweeney, and C. M. Lynch. 1998. Significance of non-starter lactic acid bacteria in Cheddar cheese. Aust. J. Dairy Technol. 53:83-89.

Guglielmotti, D., J. A. Reinheimer, A. G. Binetti, G. Giraffa, D. Carminati, and A. Quiberoni. 2006. Characterization of spontaneous phage-resistant derivatives of Lactobacillus delbrueckii commercial strains. Int. J. Food Microbiol. 111:126-133.

Herreros, M. A., R. Arenas, M. H. Sandoval, J. M. Castro, J. M. Fresno, and M. E. Tornadijo. 2007. Effect of addition of native cultures on characteristics of Armada cheese manufactured with pasteurized milk: A preliminary study. Int. Dairy J. 17:328-335.

Hynes, E., C. V. Bergamini, V. Suárez, and C. A. Zalazar. 2003. Proteolysis on Reggianito cheeses manufactured with natural whey cultures and selected strains of Lactobacillus helveticus. J. Dairy Sci. 86:3831-3840.

Hynes, E., A. Delacroix-Buchet, C. A. Meinardi, and C. A. Zalazar. 1999. Relation between $\mathrm{pH}$, degree of proteolysis and consistency in soft cheese. Aust. J. Dairy Technol. 54:24-27.

Hynes, E., A. Delacroix-Buchet, and C. A. Zalazar. 2001a. Influence of milk-clotting enzyme in proteolysis during ripening of Cremoso Argentino cheese. Aust. J. Dairy Technol. 56:208-212.

Hynes, E., J.-C. Ogier, and A. Delacroix-Buchet. 2001b. Proteolysis during ripening of miniature washed-curd cheeses manufactured with different strains of starter bacteria and a Lactobacillus plantarum adjunct culture. Int. Dairy J. 11:587-597.

International Dairy Federation (IDF). 1982. Determination of the total solid content (cheese and processed cheese). IDF Standard 4A. Brussels, Belgium.

International Dairy Federation (IDF). 1988. Yogurt: Enumeration of characteristic microorganisms. IDF Standard 117A. Brussels, Belgium.

International Dairy Federation (IDF). 1993. Milk. Determination of the nitrogen (Kjeldahl method) and calculation of the crude protein content. IDF Standard 20B. Brussels, Belgium.

International Dairy Federation (IDF). 1997. Lait et produits laitiers. Dtétermination de la teneur en matière grasse. Guide de directives génerales appliquées aux méthodes butyrometriques. 152A. Brussels, Belgium.

Kieronczyk, A., S. Skeie, T. Langsrud, and M. Yvon. 2003. Cooperation between Lactococcus lactis and nonstarter lactobacilli in the formation of cheese aroma from amino acids. Appl. Environ. Microbiol. 69:734-739.

Kleter, G. 1977. The ripening of Gouda cheese made under strictly aseptic conditions. 2 . The comparison of the activity of different starters and the influence of certain Lactobacillus strains. Neth. Milk Dairy J. 31:177-187.

Lane, C. N., P. F. Fox, E. M. Walsh, B. Folkertsma, and P. L. H. McSweeney. 1997. Effect of compositional and environmental factors on the growth of indigenous nonstarter lactic acid bacteria in Cheddar cheese. Lait 77:561-573.

Lynch, C. M., P. L. H. McSweeney, P. F. Fox, T. M. Cogan, and F. D. Drinan. 1996. Manufacture of Cheddar cheese with and without adjunct lactobacilli under controlled microbiological conditions. Int. Dairy J. 6:851-867.

Lynch, C. M., D. D. Muir, J. M. Banks, P. L. H. McSweeney, and P. F. Fox. 1999. Influence of adjunct cultures of Lactobacillus paracasei ssp. paracasei or Lactobacillus plantarum on Cheddar cheese ripening. J. Dairy Sci. 82:1618-1628.

Macedo, A. C., T. G. Tavares, and F. X. Malcata. 2004. Influence of native lactic acid bacteria on the microbiological, biochemical and sensory profiles of Serra da Estrela cheese. Food Microbiol. 21:233-240.
Macedo, A. C., M. Vieira, R. Poças, and F. X. Malcata. 2000. Peptide hydrolase system of lactic acid bacteria isolated from Serra da Estrela cheese. Int. Dairy J. 10:769-774.

Martínez-Cuesta, M. C., P. Fernández de Palencia, T. Requena, and C. Peláez. 2001. Enzymatic ability of Lactobacillus casei subsp. casei IFPL731 for flavour development in cheese. Int. Dairy J. 11:577-585.

Martley, F. G., and V. L. Crow. 1993. Interaction between nonstarter microorganisms during cheese manufacture and ripening. Int. Dairy J. 3:461-483.

McKay, L. L., and K. A. Baldwin. 1974. Simultaneous loss of proteinase and lactose utilizing enzymes activities in Lactococcus and reversal of loss by transduction. Am. Soc. Microbiol. 20:342-346.

McSweeney, P. L. H., E. M. Walsh, P. F. Fox, T. M. Cogan, F. D. Drinan, and M. Castelo-Gonzalez. 1994. A procedure for the manufacture of Cheddar cheese under controlled bacteriological conditions and the effect of adjunct lactobacilli on cheese quality. Irish J. Agric. Food Res. 33:183-192.

Mendia, C., F. J. Iban $\rightarrow$ ez, P. Torre, and Y. Barcina. 2000. Effect of pasteurization and use of a native starter culture on proteolysis in a ewes' milk cheese. Food Contr. 11:195-200.

Mercanti, D. J., M. M. Milesi, and E. Hynes. 2006. Fermentos de lactobacilos mesófilos para quesería. Pages 381-385 in Proc. $9^{\circ}$ Congresso Pan-americano do Leite, FEPALE, Porto Alegre, Brazil.

Moineau, S., and C. Lévesque. 2005. Control of bacteriophages in industrial fermentations. Pages 285-296 in Bacteriophages: Biology and Applications. E. Kutter and A. Sulakvelidze, ed. CRC Press, Boca Raton, FL.

Naylor, J., and M. E. Sharpe. 1958. Lactobacilli in Cheddar cheese. III. The source of lactobacilli in cheese. J. Dairy Res. 25:431-438.

Peterson, S. D., and R. T. Marshall. 1990. Nonstarter lactobacilli in Cheddar cheese: A review. J. Dairy Sci. 73:1395-1410.

Quiberoni, A., P. Tailliez, P. Quénee, V. Suárez, and J. A. Reinheimer. 1998. Genetic (RAPD-PCR) and technological diversities among wild Lactobacillus helveticus strains. J. Appl. Microbiol. 85:591-596

Reddy, K. A., and E. H. Marth. 1993. Proteolysis in cheddar cheese made with sodium chloride, potassium chloride or mixtures of sodium and potassium chloride. Lebensm. Wiss. Technol. 26:434-442.

Sánchez, I., S. Seseña, J. M. Poveda, L. Cabezas, and L. Palop. 2006. Genetic diversity, dynamics, and activity of Lactobacillus community involved in traditional processing of artisanal Manchego cheese. Int. J. Food Microbiol. 107:265-273.

Shakeel-Ur-Rehman, J., M. Banks, E. Y. Brechany, D. D. Muir, P. L. H. McSweeney, and P. F. Fox. 2000a. Influence of ripening temperature on the volatiles and flavour of Cheddar cheese made from raw or pasteurised milk. Int. Dairy J. 10:55-65.

Shakeel-Ur-Rehman, J., M. Banks, P. L. H. McSweeney, and P. F. Fox. 2000b. Effect of ripening temperature on the growth and significance of non-starter acid bacteria in Cheddar cheese made from raw or pasteurised milk. Int. Dairy J. 10:45-53.

Shakeel-Ur-Rehman, P., F. Fox, and P. L. H. McSweeney. 2000c. Methods used to study non-starter microorganisms in cheese: A review. Int. J. Dairy Technol. 53:113-119.

Somers, E. B., M. E. Johnson, and A. C. L. Wong. 2000. Biofilm formation and contamination of cheese by nonstarter lactic acid bacteria in the dairy environment. J. Dairy Sci. 84:1926-1936.

Stanley, G. 1998. Microbiology of fermented milk products. Pages 50-79 in The Technology of Dairy Products. R. Early, ed. Blackie Academic \& Professional, London, UK.

Svensson, U., and A. Christiansson. 1991. Methods for phage monitoring. Pages 29-39 in Bulletin 263. Int. Dairy Fed. (IDF), Brussels, Belgium

Swearingen, P. A., D. J. O'Sullivan, and J. J. Warthsehen. 2001. Isolation, characterisation and influence of native, nonstarter lactic acid bacteria on Cheddar cheese quality. J. Dairy Sci. 84:50-59. 
Thage, B. V., M. L. Broe, M. H. Petersen, M. A. Petersen, M. Bennedsen, and Y. Ardö. 2005. Aroma development in semihard reduced-fat cheese inoculated with Lactobacillus casei with different aminotransferase profiles. Int. Dairy J. 15:795-805.

Thomas, T. 1987. Cannibalism among bacteria found in cheese. $\mathrm{N}$. Z. J. Dairy Sci. Technol. 22:215-219.

Turner, K. W., R. C. Lawrence, and J. Lelievre. 1986. A microbiological specification for milk for aseptic cheese making. N. Z. J. Dairy Sci. Technol. 21:249-254.

Vinderola, C. G., and J. A. Reinheimer. 2000. Enumeration of Lactobacillus casei in the presence of Lactobacillus acidophilus, bifidobacteria and lactic starter bacteria in fermented dairy products. Int. Dairy J. 10:271-275.
Williams, A. G., and J. M. Banks. 1997. Proteolytic and other hydrolytic enzyme activities in non-starter lactic acid bacteria (NSLAB) isolated from Cheddar cheese manufactured in the United Kingdom. Int. Dairy J. 7:763-774.

Williams, A. G., J. Noble, J. Tammam, D. Lloyd, and J. M. Banks. 2002. Factors affecting the activity of enzymes involved in peptide and amino acid catabolism in non-starter lactic acid bacteria isolated from Cheddar cheese. Int. Dairy J. 12:841-852.

Williams, A. G., S. E. Withers, and J. M. Banks. 2000. Energy sources of non starter lactic acid bacteria isolated from Cheddar cheese. Int. Dairy J. 10:17-23.

Yvon, M. 2006. Key enzymes for flavour formation by lactic acid bacteria. Aust. J. Dairy Technol. 61:16-24. 